\title{
Electrical stimulation of hyoid muscles in post-stroke dysphagia
}

\author{
Petr Konecny ${ }^{\mathrm{a}, \mathrm{b}, \mathrm{d},}$, Milan Elfmark ${ }^{\mathrm{b}}$
}

\begin{abstract}
Aims. The purpose of this study was to evaluate swallowing changes in post-stroke patients with dysphagia after four weeks of suprahyoid muscles electrical stimulation.

Methods. This was a prospective randomized study of early stage stroke patients with dysphagia. Electrical stimulation of suprahyoid muscles was given to a group of 54 patients ( 26 men, average age 70 years) for 20 minutes a day, 5 days a week. Standard orofacial rehabilitation without electrical stimulation was carried out on a control group of 54 patients ( 31 men, average age 69 years). Swallowing was evaluated at the beginning of the study and at the end, by videofluoroscopy - measuring the time for oral and pharyngeal phases.

Results. The difference in duration of oral transit time (OTT) after the therapy between the study group (average: 0.55 \pm 0.01 ) and the control group (average: $0.29 \pm 0.03$ ) was statistically significant $(P=0.01)$. Difference in duration of the pharyngeal transit time (PTT) after the therapy between the study group (average: $0.37 \pm 0.02$ ) and control group (average: $0.15 \pm 0.02)$ was also statistically significant $(P=0.009)$.

Conclusion. Electrical stimulation of suprahyoid muscles significantly reduced the duration of the oral and pharyngeal phases: in the post-stroke patients with dysphagia used in this study. The result is improved swallowing. This is a recently recommended approach and your study confirms its efficacy.
\end{abstract}

Key words: stroke, dysphagia, electrical stimulation, suprahyoid muscles, videofluoroscopy

Received: May 29, 2017; Accepted with revision: October 4, 2017; Available online: November 2, 2017 https://doi.org/10.5507/bp.2017.043

${ }^{a}$ Department of Rehabilitation NMB Brno and CLR SMN Prostejov, Czech Republic

${ }^{b}$ Department of Physiotherapy, Faculty of Health Sciences, Palacky University Olomouc, Czech Republic

'Department of Neurology, Faculty of Medicine and Dentistry, Palacky University Olomouc and University Hospital Olomouc, Czech Republic ${ }^{d}$ Medical clinic Ordinace FBLR Elpis Olomouc, Czech Republic

Corresponding author:Petr Konecny, e-mail:dr.petr.konecny@gmail.com

\section{INTRODUCTION}

Post-stroke dysphagia manifests as a swallowing disorder. The incidence of dysphagia in patients after cerebrovascular accident is $20 \%-65 \%$ (ref. ${ }^{1,2}$ ). A complex interdisciplinary approach is needed for diagnostics and therapy ${ }^{3}$. Objective x-ray-based method - the videofluoroscopic swallowing study (VFSS) is used for evaluating a person's swallowing ability. During the VFSS video recordings of the swallowing act are evaluated and duration of different swallowing phases measured. The oral phase is determined by the so-called oral transit time (OTT). OTT is measured from the start of bolus passage from the mouth to the back of the tongue - entrance into the pharynx. Pharyngeal transit time (PTT) is measured from the time that the bolus enters the pharynx to the moment it reaches the cricopharyngeal area (beginning of the oesophagus) (ref. ${ }^{4}$ ).

Compensatory and therapeutic strategies are used in the management of swallowing disorders. Compensatory strategies ensure food intake by substitute nutrition (nasogastric intubation, percutaneous endoscopic gastrostomy or parenteral intravenous nutrition), by selection of suitable food and by modification of food consistency. Therapeutic strategies restore the oropharyngeal motor skills and swallowing maneuvers with the help of therapeutic exercise. This is orofacial rehabilitation (OFR) $\left(\right.$ ref $\left.^{4-7}\right)$. Our standard OFR therapy included 3 steps. Step 1 (Preparatory phase): postural therapy and respiratory rehabilitation with practise to close the laryngeal strait. Step 2 (Practise of "dry" swallowing): practising the oral phase (exercise of tongue, thermal touch therapy, exercising face and lip muscles) and pharyngeal phase (strenuous swallowing training with the pressure of tongue on palate and strengthening vocal cord closure). Step 3 (Targeted physiotherapy of swallowing): Practise of swallowing with the use of foods and drinks of different consistency, activation of the propulsion force, training of the supraglotic swallowing and eventually practise of the compensation swallowing strategy with the help of controlled head position ${ }^{7}$. OFR has impact not only on the restoration of the swallowing but also on the other orofacial functions (mimics, speech), overall health and life quality ${ }^{4,8}$. A newly recommended approach for the functional restoration of swallowing muscles is electrical stimulation (ES) of hyoid muscles. ES of hyoid muscles in post-stroke patients with dysphagia leads to improved elevation of the larynx and better closure of the airways and therefore it prevents food aspiration ${ }^{9,}{ }^{10}$. The most clinically useful approach is to stimulate the suprahyoid muscles by means of TENS (transcutaneous electrical nerve stimulation) currents with a frequency of $60 \mathrm{~Hz}$, a pulse length of $300 \mathrm{~ms}$ and intensity of the motor threshold $^{9-12}$. 
The purpose of our prospective study was to objectively evaluate with the help of VFSS, the changes in swallowing times (OTT and PTT) in post-stroke patients with dysphagia after four weeks of OFR therapy with ES of suprahyoid muscles compared to patients (control group) who received standard OFR without ES.

\section{METHODS}

Inclusion criteria were dysphagia in the early stage after stroke, ability of active cooperation and negative watertest (excluding aspiration) ${ }^{13}$. All patients signed informed consent and the study was performed in accordance with the Declaration of Helsinki ethical principles for medical research.

The study group comprised of 54 patients, 28 women and 26 men of average age 70 years. Of these, 50 patients had ischemic stroke and 4 patients had hemorrhagic stroke. Brainstem damage with bulbar palsy was present in seven cases. Cortical-subcortical damage with pseudobulbar palsy was present in 47 patients. The control group included 54 patients, 23 women and 31 men of average age 69 years. Of these, 49 patients had ischemic stroke and 5 had hemorrhagic stroke. Ten patients with brainstem lesion suffered bulbar palsy and 44 developed pseudobulbar palsy due to cortical-subcortical brain lesion (Table 1). We used instrumental examination - VFSS for the evaluation of swallowing. Duration of the oral transit time (OTT) and the pharyngeal transit time (PTT) was measured. Measurements were performed during the patient's hospitalization at the rehabilitation departments of NMB in Brno and CLR in Prostějov hospital. We measured the values at the beginning of the rehabilitation therapy (before OFR) and after four weeks of therapy (after OFR). Our study took place between January 2013 and December 2016. Standard OFR was performed in both groups once a day five days a week ${ }^{14}$. Furthermore electrical stimulation of the suprahyoid muscles by means of TENS currents with a frequency of $60 \mathrm{~Hz}$ and intensity of the motor threshold was applied in the study group for $20 \mathrm{~min}$ a day, five days a week. Measured values for OTT and PTT times before and after the therapy and differences between the study group and the control group were statistically evaluated using ANOVA: The significance level was set at $P<0.05$.

\section{RESULTS}

In total 108 post-stroke patients with dysphagia were evaluated after four weeks of complex OFR. We found statistically significant changes in the study group treated with both OFR and ES of suprahyoid muscles. There was a difference in the oral phase (the difference in OTT was $0.55 \pm 0.01, P=0.0009$ ) and in the pharyngeal phase (the difference in PTT $=0.37 \pm 0.02, P=0.0001$ ). We also found statistically significant changes in the control group after the therapy (the difference in OTT was 0.29 $\pm 0.03, P=0.01$ and the difference in PTT was $0.15 \pm 0.02$, $P=0.009)$. When comparing the differences between the groups after the therapy we found statistically significant changes for the OTT value $P=0.01$ and for the PTT value $P=0.009$ (Table 2.).

\section{DISCUSSION}

Significant changes in the values measured by VFSS before and after the therapy and the significant differences between the groups in this intervention provide us with positive evidence for the efficiency of suprahyoid

Table 1. Demographic data.

\begin{tabular}{lccc}
\hline & $\begin{array}{c}\text { Study group } \\
(\mathrm{n}=54)\end{array}$ & $\begin{array}{c}\text { Control group } \\
(\mathrm{n}=54)\end{array}$ & $P$ \\
\hline Age (years) (SD) & $70( \pm 7.3)$ & $69( \pm 8.2)$ & NS \\
Men / women (number, \%) & $26(48 \%) / 28(52 \%)$ & $31(57 \%) / 23(43 \%)$ & NS \\
Type of stroke (ischemia /haemorrhage) & $50(92 \%) / 4(8 \%)$ & $49(91 \%) / 5(9 \%)$ & NS \\
Palsy (Pseudobulbar/ Bulbar) & $47(87 \%) / 7(13 \%)$ & $44(82 \%) / 10(18 \%)$ & NS \\
\hline
\end{tabular}

SD - standard deviation, $\mathrm{P}$ - level of statistical significance $(P<0.05)$, NS - non-significant difference, $\mathrm{n}$ - number of patients

Table 2. VFSS - transit times before and after therapy (sec.).

\begin{tabular}{lccc}
\hline & $\begin{array}{c}\text { Study group } \\
(\mathrm{n}=54)\end{array}$ & $\begin{array}{c}\text { Control group } \\
(\mathrm{n}=54)\end{array}$ & $P$ \\
\hline OTT_1 (SD) & $1.55( \pm 0.21)$ & $1.56( \pm 0.25)$ & $\mathrm{NS}$ \\
OTT_2(SD) & $1.00( \pm 0.20)$ & $1.29( \pm 0.29)$ & 0.0005 \\
PTT_1(SD) & $1.05( \pm 0.15)$ & $1.06( \pm 0.17)$ & $\mathrm{NS}$ \\
PTT_2(SD) & $0.68( \pm 0.13)$ & $0.91( \pm 0.19)$ & 0.0004 \\
\hline
\end{tabular}

SD - standard deviation, $\mathrm{P}$ - level of statistical significance $(P<0.05)$, NS - non-significant difference, $\mathrm{n}$ - number of patients OTT_1 - mean value of oral transit time before therapy, OTT_2 - mean value of oral transit time after therapy, PTT_1 - mean time of pharyngeal transit time before therapy, PTT_2 - mean value of pharyngeal transit time after therapy 
muscles ES in OFR of post-stroke dysphagias. We observed improvement in the oral and pharyngeal transit times in both groups after four weeks of therapy. The measured improvement of swallowing times (OTT and PTT) between the observed groups was significantly better in intervention group where ES had been performed. Similar results were published by Permisirivanich et al. ${ }^{15}$. This study compared the effects of four weeks rehabilitation swallowing therapy (11 post-stroke patients with dysphagia) vs. neuromuscular electrical stimulation therapy (12 post-stroke patients with dysphagia). While both RST and NMES therapy has showed a positive effect in the treatment of persistent dysphagia in stroke patients, NMES was significantly superior (evaluated according to functional oral intake scale - FOIS). We found similar results but we used VFSS instead of FOIS for the evaluation of changes.

A similar study by Ludlow et al. provided evidence that ES of the suprahyoid muscles improves swallowing after a stroke ${ }^{11}$. In contrast Power et al. found no benefit of ES. In this study ES applied to pharyngeal muscles in post-stroke patients with dysphagia for one hour daily for one month rehabilitation course had no significant functional or neurophysiological benefit in comparison with a control group that received conventional rehabilitation treatment of dysphagia ${ }^{16}$.

In our study we used ES of the suprahyoid muscles. Similar ES of suprahyoid muscles was used by Beom et. al. in patients with dysphagia after central nervous system lesions. In this study positive clinical changes in swallowing were observed in seven study subjects in comparison with 21 controls but these were not statistically significant. The lack of statistical significance may have been due to small sample size ${ }^{10}$.

\section{CONCLUSION}

A significant positive effect of ES therapy was found in our study. After four weeks of OFR with ES of suprahyoid muscles, oral and pharyngeal transit times improved in patients with dysphagia after cerebrovascular accident. The ES is a reliable and effective method for swallowing disorders therapy. Post-stroke dysphagia treatment is important for restoration of food and liquid intake. This improves basic life functions (nutrition and hydration), life quality and decreases morbidity and mortality.
Author contributions: Both authors contributed equally to preparing the manuscript.

Conflict of interest statement: The authors declare there are no conflicts of interest regarding the publication of this article.

\section{REFERENCES}

1. Herzig R, Vlachová I. Cévní onemocnění mozku a míchy. In: Kaňovský P, Herzig R. Speciální neurologie. Olomouc: Univerzita Palackého; 2007. p.7-36.

2. Martino R, Foley N, Bhogal S, Diamant N, Speechley M, Teasell R. Dysphagia after stroke. Stroke 2005;36:2756-63. doi: 10.1161/01. STR.0000190056.76543.eb

3. Václavík D, Solná G, Lasotová N, Lebedová Z, Hofmanová J, Baborová E, Komínek P, Novák F, Neubaer K. Péče o pacienty s dysfagií po cévní mozkové příhodě. Cesk Slov Neurol N 2015;78/111(6):721-7. doi: 10.14735/amcsnn2015721

4. Tedla M. Poruchy polykání. Halvíčkův Brod: Tobiáš; 2009.

5. Castillo Morales R. Die Orofaziale Regulationstherapie. Munchen, Berlin, Heidelberg: Pflaum; 1998.

6. Gangale DC. Rehabilitace orofaciální oblasti. Praha: Grada Publishing 2004

7. Konecny P, Elfmark M, Bastlova P, Alacova PG. New orofacial physiotherapy of dysphagia after stroke. Int J Phys Med Rehabil 2017;5:406. doi: 10.4172/2329-9096.1000406

8. Konecny P, Elfmark M, Urbanek K. Facial paresis after stroke and its impact on patients' facial movement and mental status. J Rehabil Med 2011;43(1):73-5. doi: 10.2340/16501977-0645

9. Freed ML, Freed L, Chatburn RL, Christian M. Eletrical stimulation for swallowing disorders caused by stroke. Respir Care 2001;46(5):46674.

10. Beom J, Kim JS, Han RT. Eletrical stimulation of suprahyoid muscules in brain-injured patienst with dysphagia. Ann Rehabil Med 2011;35:322-7. doi: 10.5535/arm.2011.35.3.322

11. Ludlow CL, Humbert IA, Saxon K, Poletto Ch, Sonies B, Crujido L. Effects of surface electrical stimulation both at rest and during swallowing in chornic pharyngeal dysphagia. Dysphagia 2007;22:1-10. doi: 10.1007/s00455-006-9029-4

12. Humbert IA, Michou E, MacRae PR, Crujido L. Electrical stimulation and swallowing. How much dowe know? Semin Speech Lang 2012;33(3):203-16. doi: 10.1055/s-0032-1320040

13. Daniels SK, McAdam CP, Brailey K, Foundas A. Clinical assesment of swallowing and prediction of dysphagia severity. J Speech Language Pathol 1997;6(4):17-24. doi: 10.1044/1058-0360.0604.17

14. Konečný $P$, Elfmark $M$, Horák $S$, Kadlčík $T$, Dobšák $P$, Mikulík R. Dysphagia after cerebrovascular accident. Rehabil Fyz Lék 2015;22(4):181-4. (in Czech).

15. Permsirivanich $W$, Tipchatyotin $S$, Wongchai $M$, Leelamanit $V$, Setthawatcharawanisch S, Sathirapanya P, Phabpahl K, Juntawises U, Boonmeeprakob A. Comparing the effects of rehabilitation swallowing therapy vs. neuromuscular electrical stimulation therapy among stroke patients with persistent pharyngeal dysphagia: a randomized controlled study. J Med Assoc Thai 2009;92(2):259-65.

16. Power ML, Fraser $\mathrm{CH}$, Hobson A, Singh S, Tyrell P, Nicholson DA, Turnbull I, Thompson DG, Hamdy S. Evaluating oral stimulation as a treatment for dysphagia after stroke. Dysphagia 2006;21(1):49-55. doi: 10.1007/s00455-005-9009-0 